\title{
AVALIAÇÃO DAS ALTERAÇÕES BUCAIS CAUSADAS PELO USO DE PRÓTESES REMOVÍVEIS
}

Caroline RUIZ, Luciana Cristina OLIVEIRA, Keli Cristina BERNARDO, Thayane Bertipaglia PIRES, Adriana Márcia BELOTI

A mucosa bucal é um local favorável para ocorrência de lesões descamativas, ulcerativas e vesiculosas. Podem ser causada por supressão da flora bucal normal, redução do fluxo salivar e por próteses inadequadas e/ou má higienizadas. O objetivo dessa pesquisa foi analisar as alterações bucais em pacientes usuários de próteses moveis atendidos pelo PROLEB do Curso de Odontologia do Cesumar. Os dados coletados referem-se à análise de prontuários clínicos de 132 pacientes no ano de 2007. Do total da amostra avaliada, 65,5\% eram do sexo masculino e $34,5 \%$ do sexo feminino, com idade entre 10 a 75 anos. Entre os 132 pacientes investigados, 37 (27,20\%) faziam uso de prótese, sendo esta observada em pacientes acima de 60 anos. Destes, todos apresentaram próteses em condições inadequadas ao uso. As regiões mais afetadas por lesões foram: Palato Duro (51,2\%); Vestíbulo Inferior (18,5\%); Vestíbulo Superior (16,3\%); Assoalho e Mucosa Labial (04\%). Em relação aos tipos de lesões diagnosticadas entre os usuários de próteses, as mais freqüentes foram: Candidíase (37,8\%); Hiperplasia (32,4\%); Fibroma $(13,5 \%)$ e Lesão por Trauma (5,4\%). Diante dos dados verifica-se a necessidade de programas educativos que orientem a auto-avaliação, higienização e manutenção de próteses no intuito de prevenir lesões bucais.

Palavras- chave: Odontologia Geriátrica, Mucosa Bucal, Candidíase. 